\title{
A User-Controlled Thermal Chair for an Open Plan Workplace: CFD and Field Studies of Thermal Comfort Performance
}

\author{
Sally Shahzad ${ }^{\mathrm{a}}$ 1, John Kaiser Calautit ${ }^{\mathrm{b}}$, Angelo I. Aquino ${ }^{\mathrm{c}}$, Diana SNM Nasir ${ }^{\mathrm{c}}$, Ben \\ Richard Hughes ${ }^{\mathrm{C}}$ \\ ${ }^{a}$ School of Engineering and Technology, University of Derby, Derby, DE22 3AW, UK \\ ${ }^{b}$ Department of Architecure and Built Environment, University of Nottingham, NG7 2RD, UK \\ ${ }^{c}$ Department of Mechanical Engineering, University of Sheffield, S10 2TN, UK
}

\begin{abstract}
This study aims to improve user comfort and satisfaction regarding the thermal environment in the open plan office, which is a current challenge in the workplace addressed by limited research. The main difficulty in an open plan setting is that changing the room temperature in an area affects all occupants seated nearby. This issue in addition to individual differences in perceiving the thermal environment create a great challenge to satisfy all occupants in the
\end{abstract}
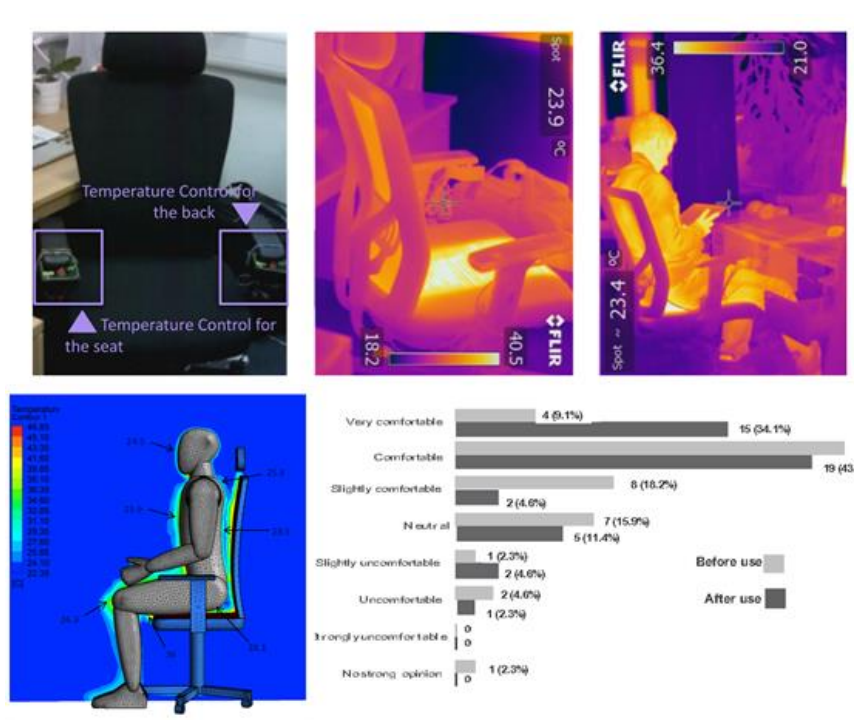

CFD ANALYSIS

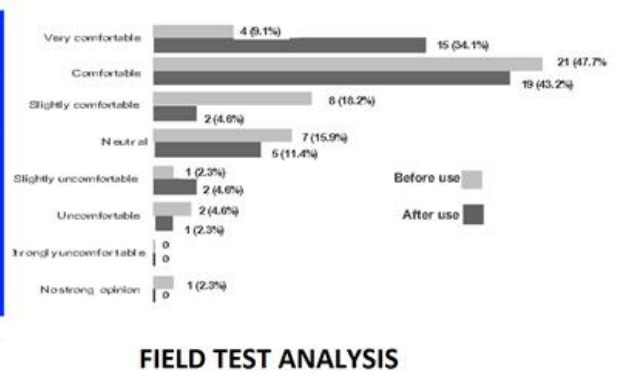

workplace. This study investigates the application of an advanced thermal system, a user-controlled thermal chair, which allows individual control over their immediate thermal environment without affecting the thermal environment and comfort of other occupants. The performance of the chair was further analysed through Computational Fluid Dynamics (CFD) simulations providing a detailed analysis of the thermal distribution around a thermal chair with a sitting manikin. The results indicated that user thermal comfort can be enhanced by improving the local thermal comfort of the occupant. A prototype of an office chair equipped with thermal control over the seat and the back was produced and examined in an open plan office in November in Leeds, UK. Forty five individuals used the chair in their everyday context of work and a survey questionnaire was applied to record their views of the thermal environment before and after using the chair. The results of the field study revealed $20 \%$ higher comfort and $35 \%$ higher satisfaction level, due to the use of thermal 
chair. Thermal measurements showed acceptable thermal conditions according to the ASHRAE Standard 55-2013. Over $86 \%$ of the occupants set the temperature settings of the seat and the back of the chair between $29^{\circ} \mathrm{C}$ and $39^{\circ} .82 \%$ of the occupants expressed their satisfaction level as "satisfied" or "very satisfied" regarding the performance of the thermal chair. The thermal chair energy consumption was relatively low $(0.03 \mathrm{~kW})$ when compared with that of typical personal heaters, which are about $1-1.5 \mathrm{~kW}$. Further research is recommended to improve the design and application of the thermal chair to improve user overall thermal comfort and also further reduce energy consumption.

Keywords: Thermal Chair; comfort; open plan office; thermal control; Computational Fluid Dynamics (CFD)

\section{Introduction}

The research in the field of thermal comfort is mainly focused on what temperatures satisfy all in order to produce standards and guidelines [1]. Individual differences in perceiving the thermal environment are ignored [2-4]. This results in actual occupant satisfaction is significantly lower rather than the predicted [5]. Hitchings argues that 'instead of talking about what temperatures feel neutral in particular places when we have already accepted this to be dynamic, the ambition may now be to reveal which techniques people are willing to employ to get through particular periods more sustainably' [6]. However, limited research is focused on different methods to provide individual user control over the thermal environment. Research suggests that providing thermal control has an important impact on user satisfaction [7] and comfort [8,9]. However, providing thermal comfort with the aim to satisfy all in an open plan office is a challenge. There are individual differences in perceiving the thermal environment [10] and a particular temperature setting cannot satisfy all $[3,11-15]$. This becomes more of a challenge when occupants share an office or a workspace and they have different temperature preferences. The difficulty is that by adjusting the temperature in an area in the office directly influences the thermal comfort of the occupants seated nearby [3]. Another challenge is to provide user thermal control for everyone in an open plan office. In an ordinary open plan office, only occupants seated around the perimeter of the building may have access to openable windows, blinds, and possibly temperature control of the radiators, assuming these options are available [16]. The research reports that users are reluctant to utilise thermal control in an open plan office even when provided for them, due to consideration for other colleagues' comfort and health, as they are aware that applying a change influences their colleagues $[3,10]$. For instance, an occupant seated next to the window may avoid opening a window even when they feel uncomfortably warm, as this may cause discomfort for other occupants seated nearby. Furthermore, providing occupants with lower energy demanding devices to control their 
immediate thermal environment allows them to remain comfortable over a wider range of ambient temperatures [17-19].

In order to address these changes, this study investigated the application of an advanced thermal control system in an open plan setting that allowed users to set their immediate thermal environment according to their requirements. and remain comfortable over a wider range of ambient temperatures. Previous works [9] have shown that allowing the indoor ambient temperature to be lowered by a few degrees can result in large energy savings because the space is heated less intensely and less often. The work will utilise Computational Fluid Dynamic (CFD) and field testing to assess the thermal comfort performance of a thermal chair which allows users to control heating that is provided directly through the surfaces of seat and backrest. Initially, Computational Fluid Dynamic (CFD) analysis will be used to simulate the thermal distribution around a manikin seated on the thermal chair. The CFD code FLUENT will be used with the Finite Volume Method (FVM) approach and the Semi-Implicit Method for Pressure-Linked Equations (SIMPLE) velocity-pressure coupling algorithm with the second order upwind discretisation. Thermal comfort levels will be calculated using the ASHRAE PMV method. The CFD results will inform the design, construction and field testing of a prototype and optimise performance. The purpose of the field experiment is to assess the effectiveness of the thermal chair at providing comfort in a realistic office environment. For this purpose, a thermal chair prototype equipped with thermal control over the seat and the back will be produced and examined in an open plan office in Leeds, UK during the winter season. The field study will examine the comfort and satisfaction of the users before and after the use of the thermal chair.

\section{Previous Related Work}

There is a contradiction between literature and practice about providing user control over the thermal environment $[20,21]$. The literature suggests the use of thermal control for occupants to increase their comfort and satisfaction $[9,22]$, because occupants use the actual and potential variations in room temperature [23]. In addition, thermal control is predicted as an important asset to the workplace in the future [8]. On the contrary, currently in practice, occupant control over the thermal environment is being replaced with centrally operated thermal systems [23] to simplify the management of thermal systems and to avoid users meddling with it [25].

In order to reduce the energy consumption of the building and to improve the thermal comfort of the user, personalised thermal control systems have been introduced and investigated [26]. Knudsen 
and Melikov (2005) investigated different personalised control systems to improve user satisfaction, comfort [27] and productivity [4]. They introduced different control systems on the desk, chair and floor level and found that a thermally controlled chair has the most impact on user satisfaction. They used a manikin in their experiments [27]. Ugursal and Culp (2013) experimented on dynamic localised airflow for different body parts [28]. Liu et. al. (2013) investigated the impact of the skin temperature and clothing and reported that localised thermal comfort increases the overall thermal comfort of the respondents [29]. Mao et. al. (2017) studied the relationship between human thermal comfort and energy consumption in sleeping environments [30]. Chowdhury et. al. (2008) studied the impact of low energy cooling technologies in the workplace using simulation and field test [31]. University of Berkeley is one of leading institutes on Personal Control Systems (PCS) research [9,32-37]. Pessut et al. (2015) state that "Personal comfort systems (PCS) are a promising technology for both improving occupants' thermal comfort and simultaneously reducing buildings' heating and cooling energy. They provide comfort by targeting a relatively small amount of energy directly onto occupants" [36]. Figure 1 illustrates Zhao et. al. (2016) design of the Personal Comfort System Chair [38]. The chair is equipped with two fans and a strips of heating element on the seat of the chair and a fan and a heating strip on the back of the seat. The mesh fabric of the chair allows the heating or ventilation to reach the person seated on the chair [38]. A rechargeable battery ( $280 \mathrm{~W} . \mathrm{hr}$ ) was used to provide the required energy for the heating elements $(16 \mathrm{~W})$ and the fans $(3.6 \mathrm{~W})$. They used a pressure sensor to reduce the energy waste. Fifteen office employees used the chair in their office and filled in a survey questionnaire, including their satisfaction levels [38]. In a different research, the team experimented on the chair when twenty three college students used the chair in an environmental chamber for a duration of fifteen minutes. Their results indicated a great improvement in occupant's thermal sensation, thermal comfort and perceived indoor air quality. Ninety two percent of the occupants found room temperatures between $18^{\circ} \mathrm{C}$ to $29^{\circ} \mathrm{C}$ comfortable, due to the use of the cooled-warmed chair [35]. 


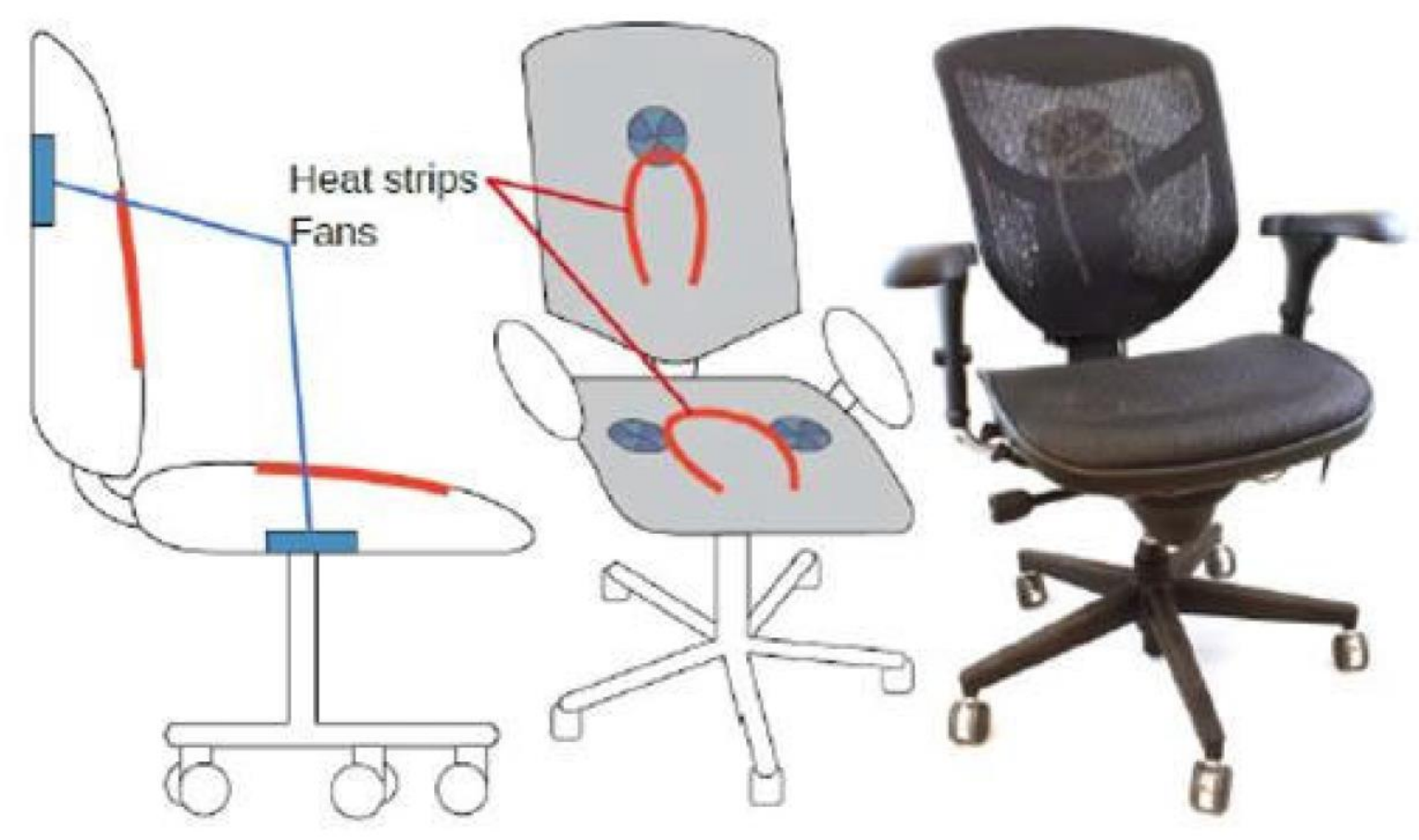

Figure 1. The Personal Comfort System Chair, UC Berkeley [38]

Watanabe et al (2009) suggests a user controlled system as a ventilated chair to improve occupant satisfaction with the thermal environment [39]. They provided an individually controlled ventilation system for the back and seat of the chair, as illustrated in Figure 2. They applied experiments in a climate chamber during the summer and their participants included seven university students. They used the ASHRAE seven point thermal sensation scale, five point comfort scale and a two point acceptability scale. They concluded that the application of a ventilated chair improves local comfort of the occupants, also that occupants felt comfortable at $30^{\circ} \mathrm{C}[39]$.
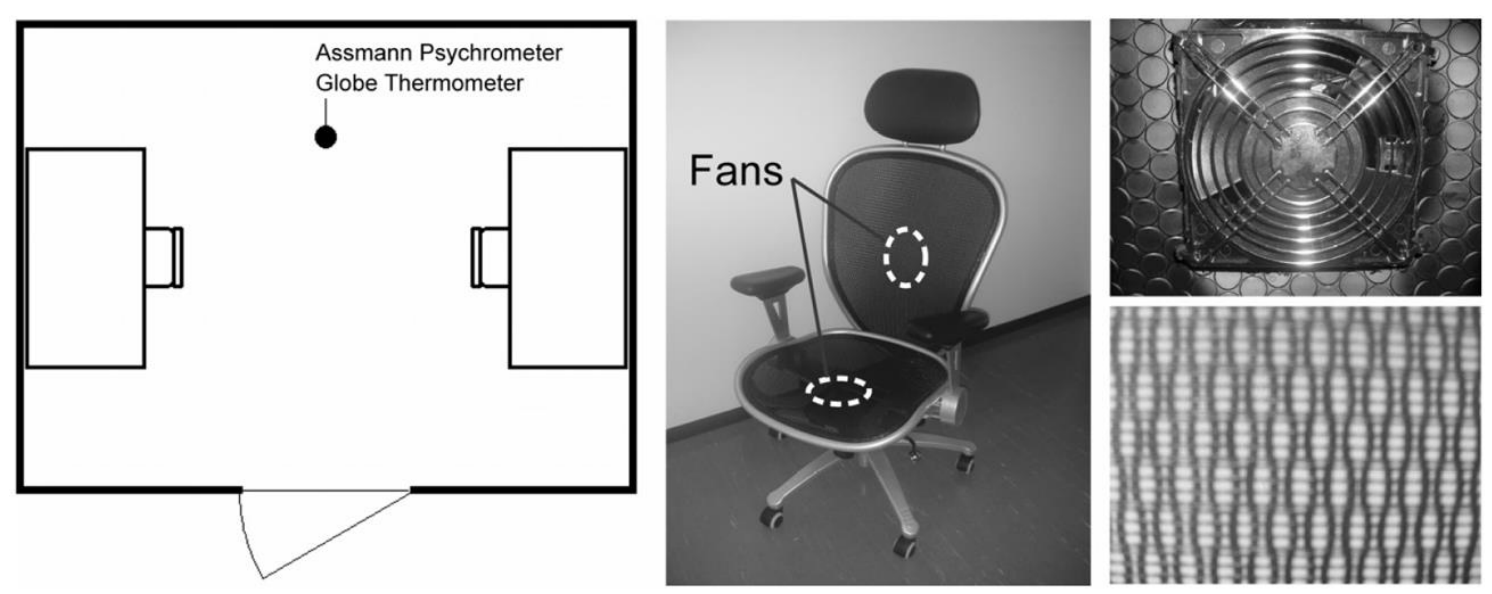

Figure 2. Ventilated chair [39] 
Ventilated office chairs in hot climates were reported as successful to cool and to improve user comfort in experimental chambers [39-41], which is called ventilated [40] or cooled chair [41], as demonstrated in Figure 3. In this prototype, the air is drawn through the back and seat of the chair and it is released through the armrests so that the ventilation allows the user to cool down. They used the thermal sensation seven point scale and found that occupants found temperatures up to $27^{\circ} \mathrm{C}$ comfortable [41-43]. Gong et al. (2008) investigated the application of a cooled chair to be used in theatres through the application of CFD analysis of a ventilated chair and human body [44]. In this study, the ventilation outlet was placed under the chair.
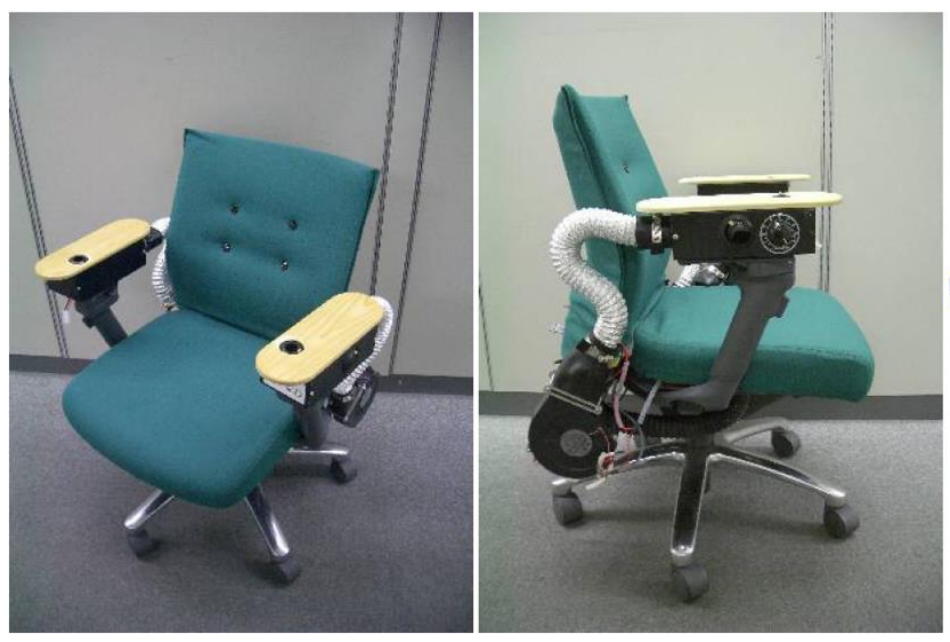

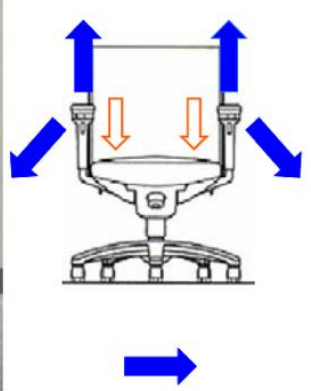

to blow out

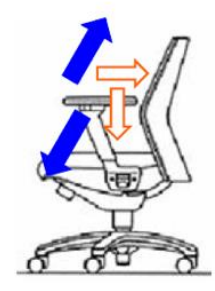

to inhale

Figure 3. Cooled Chair [41]

The successful use of heated and cooled chairs in the car industry were also reported [45, 46]. Zhang et al. (2007) used water tubes to warm or cool the car seat [47]. Pasut et al. (2013) studied the application of a heated/cooled chair (active chair) in an experimental chamber [30]. They found that the use of the active chair improves occupants' comfort and satisfaction. They found that the heating impact of the chair is more effective and satisfying for users than the cooling impact. Choi et al. (2007) examined the application of a thermoelectric device to heat and cool the car seat [45]. Their research focused on the cooling side of the thermoelectric device. Most of the research on cooled-warmed office chair is focused on the cooling effect rather than the heating effect of the chair.

This study investigated the performance of a thermal chair in an office building located in a coldtemperate climate during the heating season. Furthermore, many of the previous works were carried out in climatic chambers and only a few tested in the field. This study conducted a 
comprehensive field experiment and survey in a context of every day office environment to assess the effectiveness of the thermal chair in providing comfort. Finally, no studies investigated the performance of a heated office chair using computational methods. The research will utilise FLUENT, a Computational Fluid Dynamic (CFD) code, to simulate the thermal distribution around a thermal chair with a seated manikin.

\section{Research Methodology}

This study aims to improve user comfort through the application of a thermal chair in the workplace. It investigated the application of CFD and field studies of thermal comfort to analyse the performance of a thermal chair used in an open plan office. A prototype of an office chair equipped with separate user temperature control over the seat and the back was designed and produced, as illustrated in Figure 4. The chair seat and the back rest areas was incorporated with heating element pads covered by the chair fabric. Each pad uses up to $30 \mathrm{~W}$. Surface temperature measurements in Figure 5 (left) shows the typical temperature at various settings: 30\% (low), 60\% (medium) and 100\% (high) while the corresponding average energy usage are shown in Figure 5 (right).

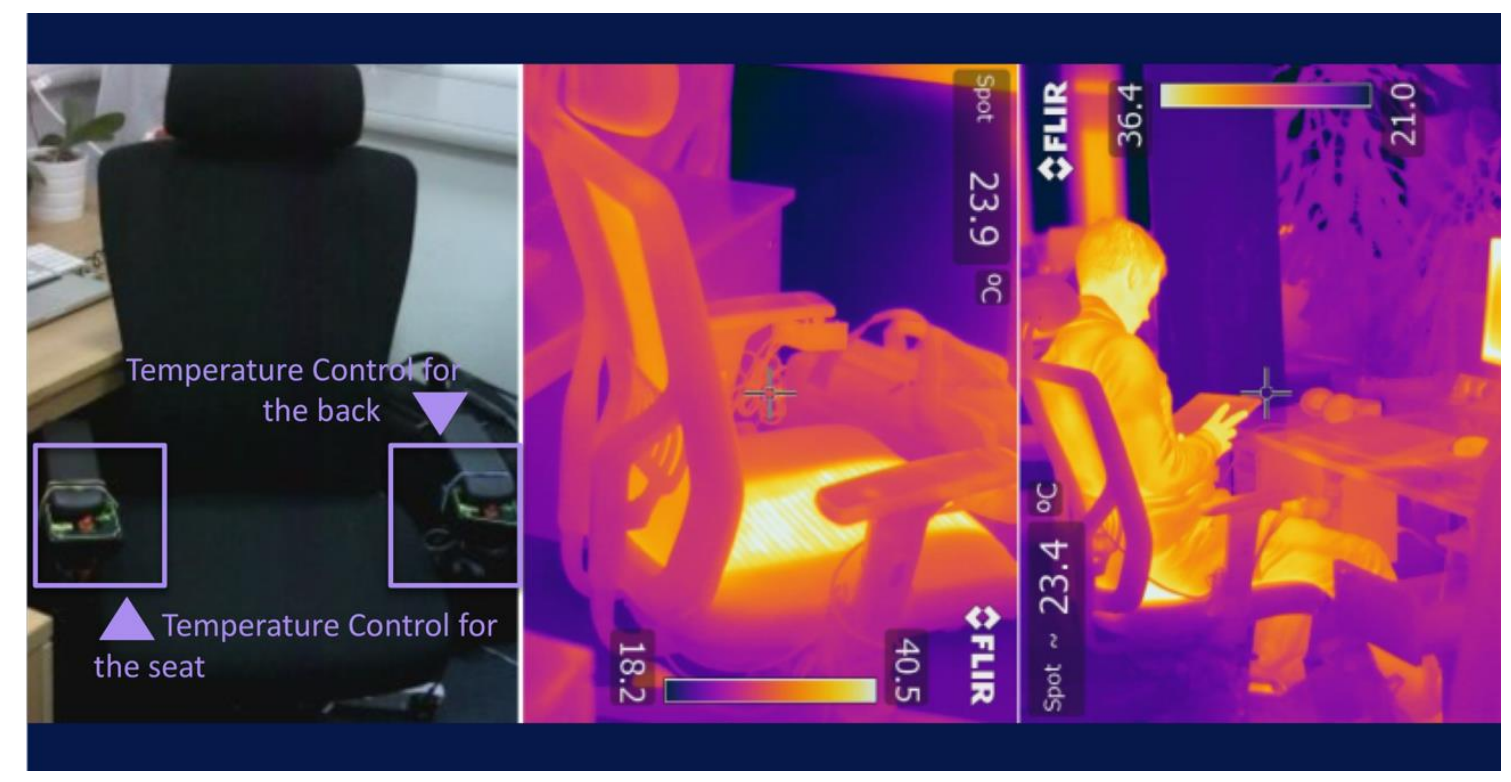

Figure 4. Thermal chair: (left) design, (middle) thermal image of seat temperature (FLIR T660) and (right) in use 

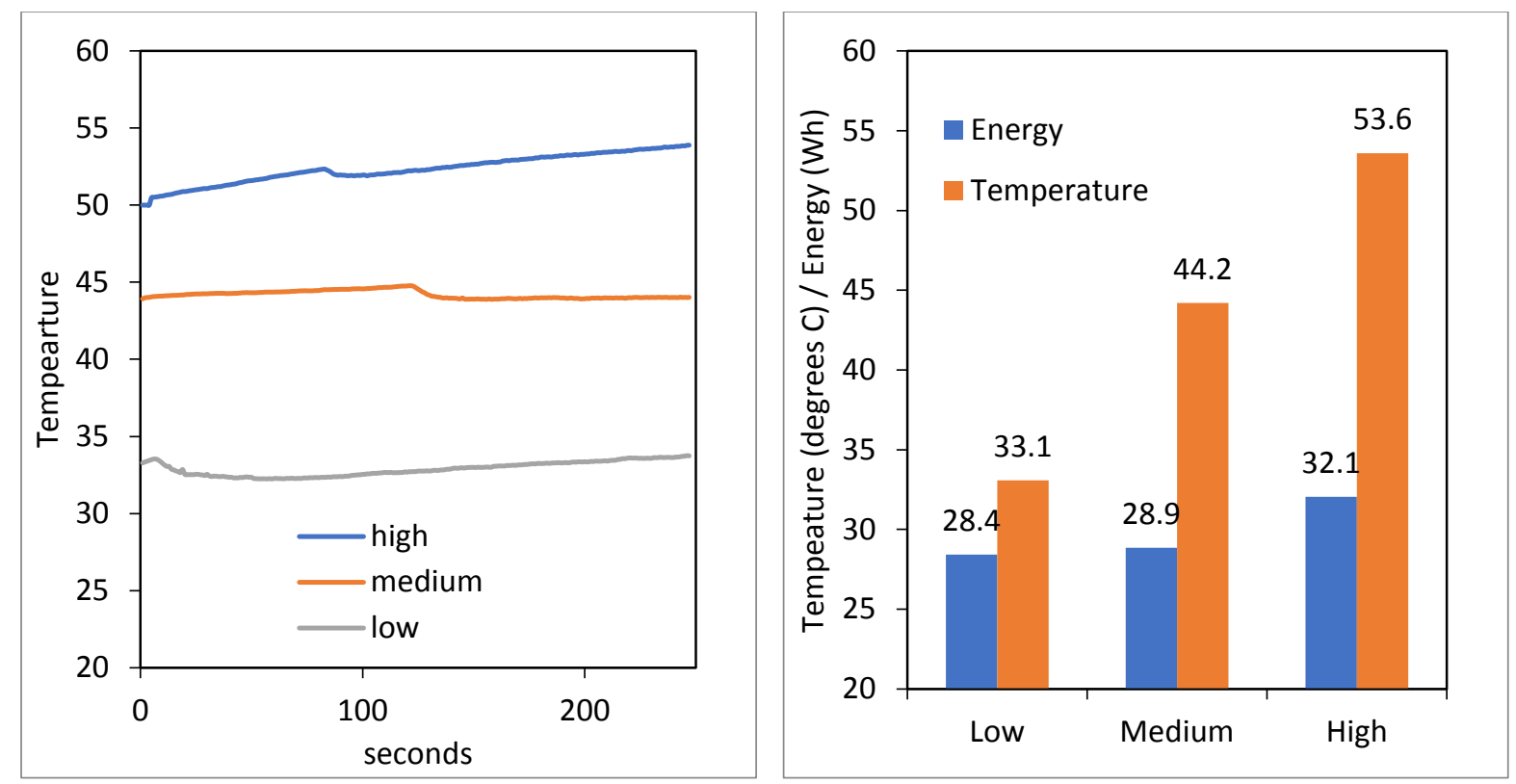

Figure 5. (left) Thermocouple temperature measurements of the surface of heating element pads and (right) average temperature and energy measurements at various settings.

\subsection{Computational Fluid Dynamics (CFD) modelling}

The basic assumptions for the CFD simulation include a three-dimensional, fully turbulent, and incompressible flow. The CFD code was used with the Finite Volume Method (FVM) approach and the Semi-Implicit Method for Pressure-Linked Equations (SIMPLE) velocity-pressure coupling algorithm with the second order upwind discretisation. The k-epsilon transport model was employed for the air turbulence due to its well-documented performance in predicting indoor airflows [48]. The general governing equations include the continuity, momentum and energy balance for each individual phase. The transport equations are formulated in Eqn. 10 and Eqn. 11. The transport equations are formulated below [49].

$$
\begin{aligned}
& \frac{\partial}{\partial t}\left(\alpha_{q} \rho_{q}\right)+\nabla \cdot\left(\alpha_{q} \rho_{q} \vec{v}_{q}\right)=\sum_{p=1}^{n}\left(\dot{m}_{\mathrm{pq}}-\dot{m}_{\mathrm{qp}}\right)+S_{q} \\
& \frac{\partial}{\partial t}\left(\alpha_{q} \rho_{q} \vec{v}_{q}\right)+\nabla \cdot\left(\alpha_{q} \rho_{q} \vec{v}_{q} \vec{v}_{q}\right)=-\alpha_{q} \nabla p+\nabla \cdot \overline{\bar{\tau}}_{q}+\alpha_{q} \rho_{q} \vec{g}+\sum_{p=1}^{n}\left(\vec{R}_{p q}+\dot{m}_{p q} \vec{v}_{p q}-\dot{m}_{q p} \vec{v}_{q p}\right)+\left(\vec{F}_{q}+\vec{F}_{\mathrm{lit}, q}+\vec{F}_{\mathrm{vm}, q}\right) \\
& \frac{\partial}{\partial t}\left(\alpha_{q} \rho_{q} h_{q}\right)+\nabla \cdot\left(\alpha_{q} \rho_{q} \vec{u}_{q} h_{q}\right)=\alpha_{q} \frac{\partial p_{q}}{\partial t}+\overline{\bar{\tau}}_{q}: \nabla \vec{u}_{q}-\nabla \cdot \vec{q}_{q}+S_{q}+\sum_{p=1}^{n}\left(Q_{p q}+\dot{m}_{p q} h_{p q}-\dot{m}_{q p} h_{q p}\right)
\end{aligned}
$$

where; $\vec{v}_{q}$ represents the velocity of phase q and $\dot{m}_{p q}$ and $\dot{m}_{q p}$ characterizes the mass transfer from the pth to qth phase and vice-versa. $\overline{\bar{\tau}}_{q}$ represents the qth phase stress-strain tensor. $\mathrm{h}_{\mathrm{q}}$ represents the specific enthalpy of the qth phase and $\vec{q}_{q}$ represents the heat flux. $Q_{p q}$ represents the intensity 
of heat exchange between the pth and qth phases and $h_{p q}$ is the interface enthalpy. $S_{q}$ represents the source term.

$$
\begin{aligned}
& \frac{\partial}{\partial t}(p k)+\frac{\partial}{\partial x_{i}}\left(\rho k u_{i}\right)=\frac{\partial}{\partial x_{j}}\left[\left(\mu+\frac{\mu_{t}}{\sigma_{k}}\right) \frac{\partial k}{\partial x_{j}}\right]+G_{k}+G_{b}-\rho \epsilon-Y_{M}+S_{k} \\
& \frac{\partial}{\partial t}(\rho \epsilon)+\frac{\partial}{\partial x_{i}}\left(\rho \epsilon u_{i}\right)=\frac{\partial}{\partial x_{j}}\left[\left(\mu+\frac{\mu_{t}}{\sigma_{e}}\right) \frac{\partial e}{\partial x_{j}}\right]+C_{1 \epsilon} \frac{\epsilon}{k}\left(G_{k}+C_{3 \epsilon} G_{b}\right)-C_{2 \epsilon} \rho \frac{e^{2}}{k}+S_{\epsilon}
\end{aligned}
$$

where; $G_{k}$ represents the generation of turbulence kinetic energy due to the mean velocity gradients, $G_{b}$ represents the generation of turbulence kinetic energy due to buoyancy. $Y_{M}$ represents the contribution of fluctuating dilatation in compressible turbulence to the overall dissipation rate. $C_{1 \epsilon}, C_{2 \epsilon}$ and $C_{3 \epsilon}$ are constants, $\sigma_{k}$ and $\sigma_{e}$ are the turbulent Prandtl numbers for k and $\varepsilon$. $S_{k}$ and $S_{\epsilon}$ are the source terms.

\subsubsection{Computational geometry}

The geometry (Figure 6) was created using CAD software and then imported into ANSYS to create a computational model. In this study a sitting manikin was used to analyse the impact of the thermal chair on the prediction of airflow velocity and temperature field. Figure 6 shows the geometry of the thermal chair with the manikin (1.8m standing height) inside the computational domain $(4.8 \mathrm{~m}$ width $\times 3.8 \mathrm{~m}$ length $\times 3 \mathrm{~m}$ height). The computational domain consisted of an inlet on one side of the domain, and an outlet on the opposing boundary wall with the thermal chair located centrally.

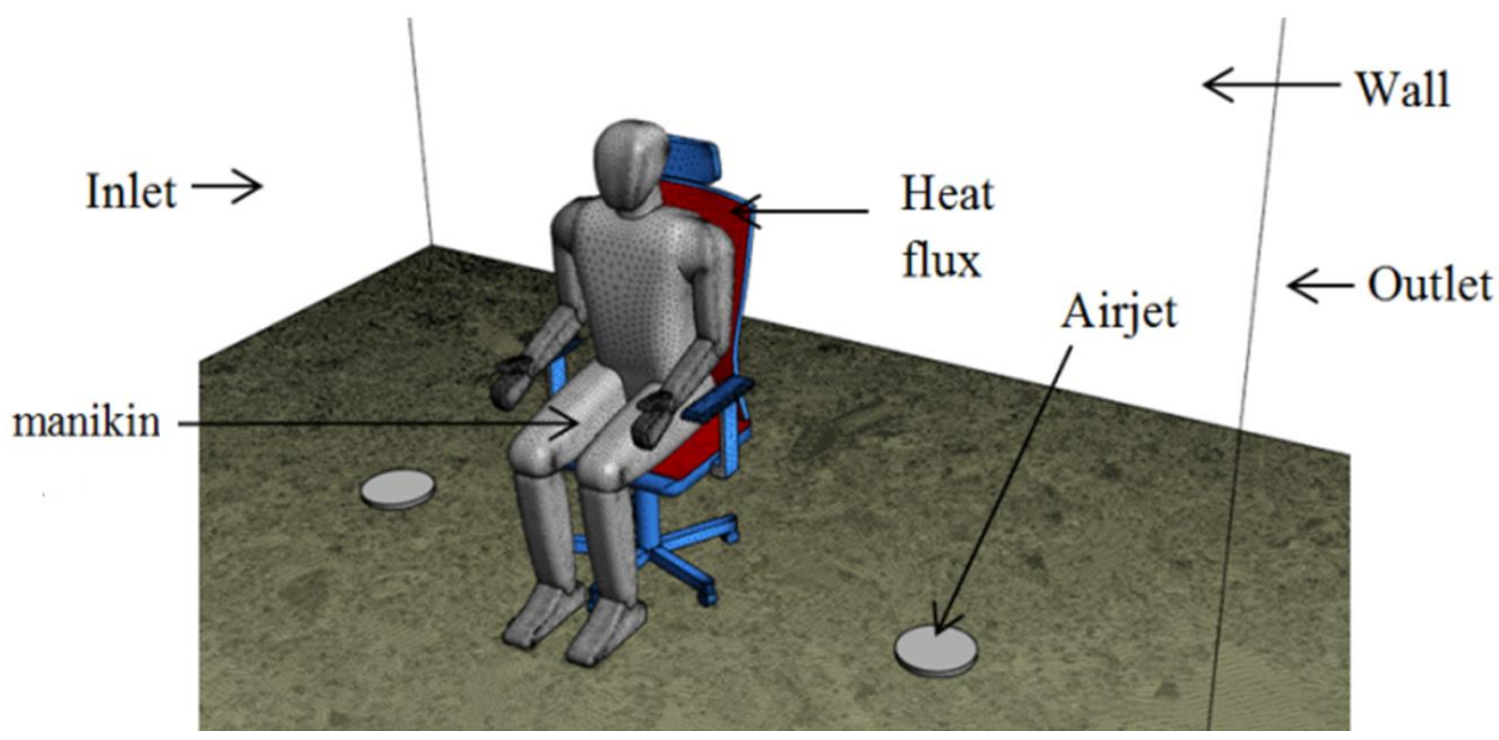

Figure 6. Computational domain for the analysis of office thermal chair with manikin model

3.1.2 Computational mesh, verification and sensitivity analysis 
Due to the complexity of the model, a non-uniform mesh was applied to volume and surfaces of the computational domain $[50,51]$. The generated computational mesh is shown in Figure 7 . The mesh was modified and refined according to the critical areas of interests in the simulation. The size of the mesh element was extended smoothly to resolve the areas with high gradient mesh and to improve the accuracy of the results. Sensitivity analysis was used to verify the computational modelling of the thermal chair with manikin. The sensitivity analysis was performed by conducting additional simulations with same domain and boundary conditions but with various mesh sizes (coarse, medium and fine mesh). The average value of the airflow velocity in the vertical line was used as the error indicator (Figure 7). The average error between the fine and coarse mesh was $5.4 \%$ or \pm 0.032 $\mathrm{m} / \mathrm{s}$. Thus, the repetition of numerical model with finer mesh had no considerable effects on the results.
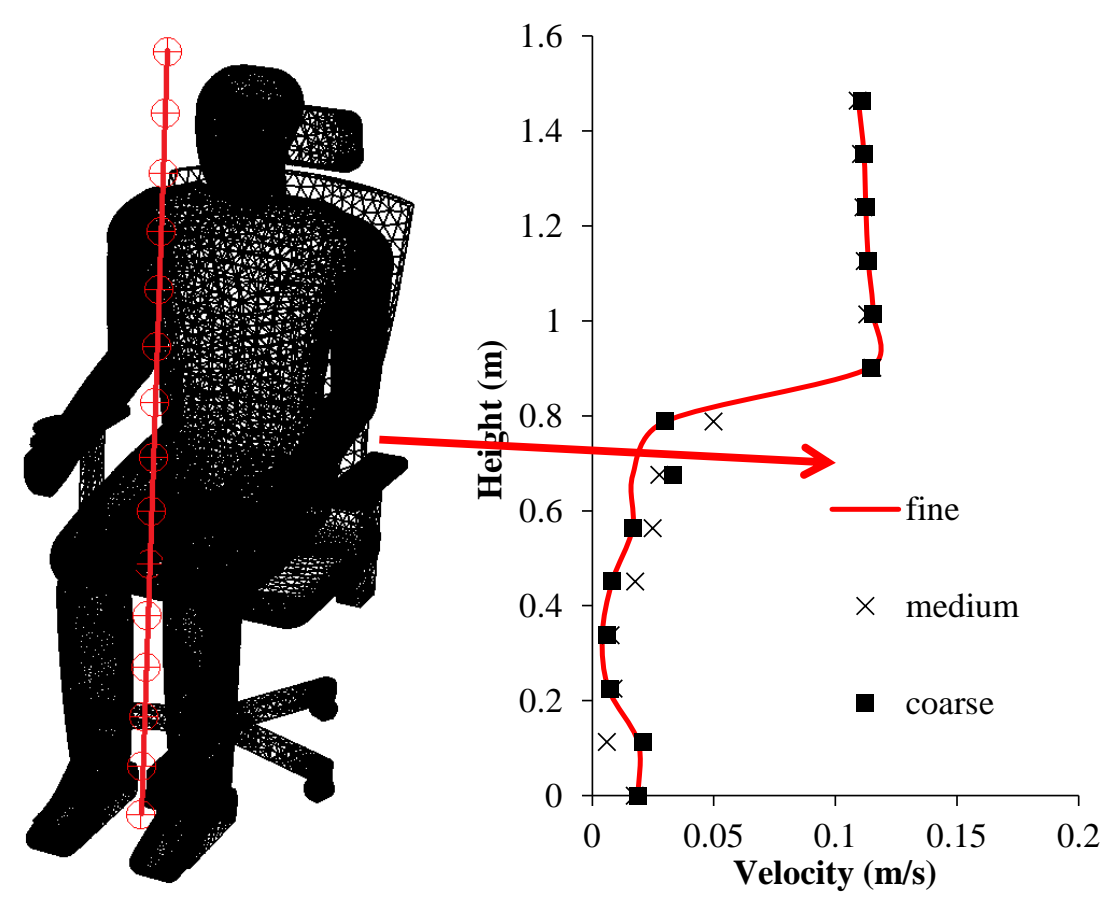

Figure 7. Grid sensitivity analysis

The convergence of the solution and relevant variables were monitored and the solution was completed when there were no changes between iterations (Figure 8). In addition, the property conservation was also checked if achieved. This was carried out by performing a mass flux balance for the converged solution. This option was available in the FLUENT flux report panel which allows computation of mass flow rate for boundary zones. For the current simulation, the mass flow rate balance was below the required value or $<1 \%$ of smallest flux through domain boundary (inlet and outlet). 

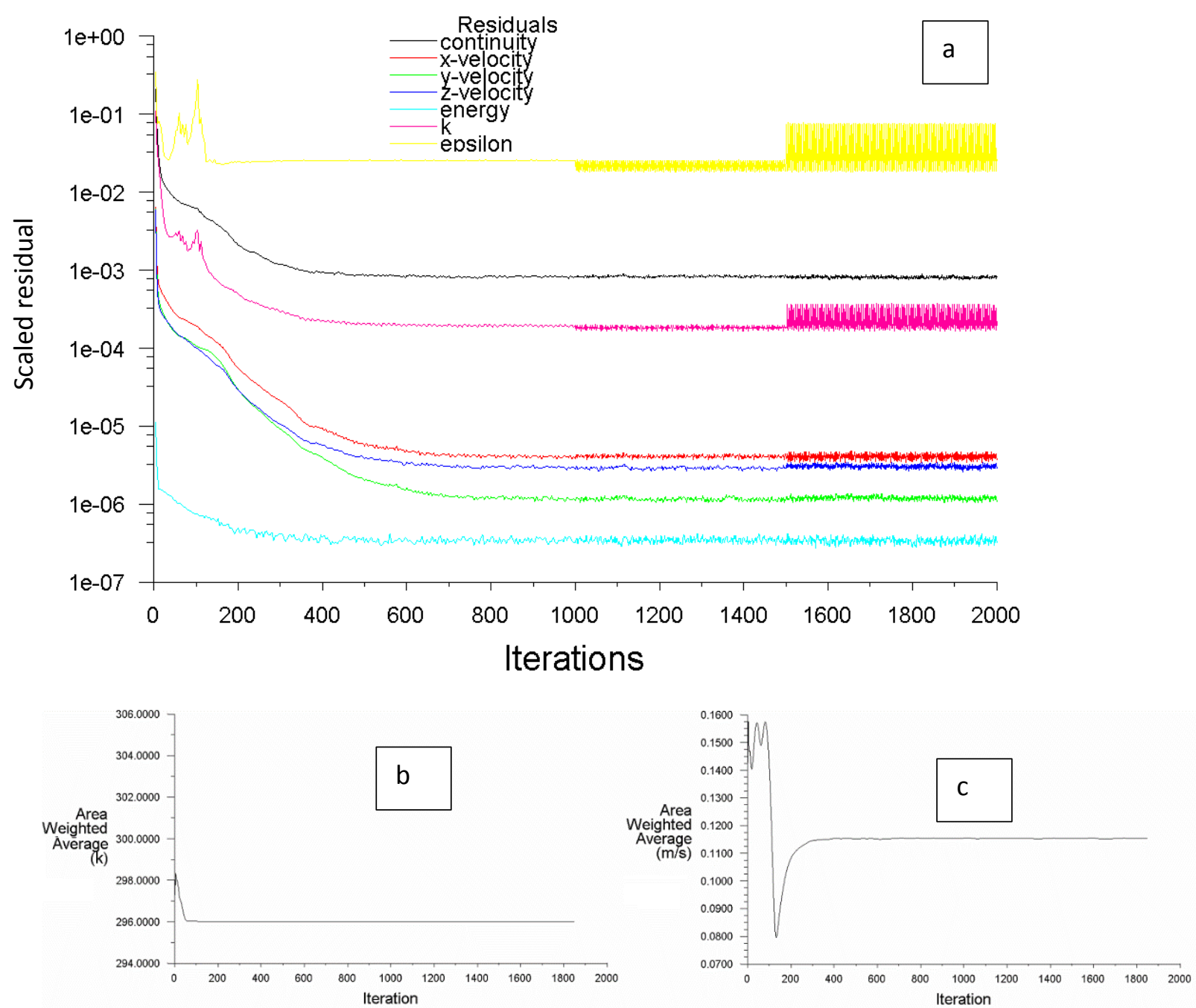

Figure 8. (a) Solution convergence (b) solution monitoring of airflow temperature (c) solution monitoring of airflow velocity

\subsubsection{Boundary conditions}

One side of the computational domain was set as velocity inlet (set at $0.1 \mathrm{~m} / \mathrm{s}$ and $23^{\circ} \mathrm{C}$ ) and the opposite wall as pressure outlet. Two configurations were simulated; (a) an office chair with heated seat (heat flux: $40 \mathrm{~W} / \mathrm{m} 2$ ) and back rest (heat flux: $40 \mathrm{~W} / \mathrm{m} 2$ ) and (b) a standard non-heated office chair and $250 \mathrm{~mm}$ diameter underfloor air jets (set at $0.2 \mathrm{~m} / \mathrm{s}$ and $25^{\circ} \mathrm{C}$ ). It should be noted that the manikin in the study was only intended to replicate the physical shape of a sitting person. The heat released by the manikin on the surrounding airflow field was also simulated by applying a heat load (a total heat load of $89 \mathrm{~W}$ ) at the manikin surface $[52,53]$, while the radiation was not considered in this study. The study by [52] details the impact of simplified methods on thermal airflow fields in the vicinity of surfaces.

\subsection{Field studies of thermal comfort}


Different researchers have applied both experimental chambers and field studies of thermal comfort to investigate the design and application of individual control systems. Kroner (2006) studied the impact of personalised thermal control in the daily context of an open plan office [54]. Luo et al. (2014) applied field studies of thermal comfort to compare thermal control in two office buildings in different climatic conditions [55]. This study aimed to investigate the subject in the context of every day life comparing user comfort and satisfaction before and after using the thermal chair. Therefore field studies of thermal comfort were applied to investigates users' views of the thermal chair in an open plan office in November in Leeds, UK. The average of the indoor dry bulb temperature was $24.1^{\circ} \mathrm{C}$ and the average of the indoor relative humidity was $29.32 \% \mathrm{RH}$. The PMV calculations are presented in section 4. Forty four occupants participated in the research by seating on the chair for the duration of an hour per person during the working hours. Participants were wearing normal indoor winter clothing. Mainly sedentary activities took place in the office and the participants were asked to go about their work as usual both before and after using the thermal chair. Their views of the thermal chair was recorded before and after the use of the chair through a survey questionnaire based on the ASHRAE seven point scale thermal sensation, comfort and satisfaction [56], as presented in Table 1 . The mobile survey method which included multiple choice questionnaire displayed on a portable device screen allowed instant and direct individual feedback.

Table 1. Survey questions based on the ASHRAE seven-point scale [56]

\begin{tabular}{|c|c|c|c|c|c|c|c|}
\hline \multicolumn{8}{|c|}{ Currently at my desk regarding the thermal environment, I feel: } \\
\hline $\begin{array}{l}\text { Very } \\
\text { comfortable }\end{array}$ & Comfortable & $\begin{array}{l}\text { Slightly } \\
\text { comfortable }\end{array}$ & Neutral & $\begin{array}{l}\text { Slightly } \\
\text { uncomfortable }\end{array}$ & Uncomfortable & $\begin{array}{l}\text { Very } \\
\text { uncomfortable }\end{array}$ & $\begin{array}{l}\text { No strong } \\
\text { opinion }\end{array}$ \\
\hline 3 & 2 & 1 & 0 & -1 & -2 & -3 & \\
\hline \multicolumn{8}{|c|}{ Currently at my desk, the overall environment makes me feel: } \\
\hline $\begin{array}{l}\text { Very } \\
\text { satisfied }\end{array}$ & Satisfied & $\begin{array}{l}\text { Slightly } \\
\text { satisfied }\end{array}$ & Neutral & $\begin{array}{l}\text { Slightly } \\
\text { dissatisfied }\end{array}$ & Dissatisfied & Very dissatisfied & $\begin{array}{l}\text { No strong } \\
\text { opinion }\end{array}$ \\
\hline 3 & 2 & 1 & 0 & -1 & -2 & -3 & \\
\hline \multicolumn{8}{|c|}{ Currently, my overall body feels: } \\
\hline Hot & Warm & $\begin{array}{l}\text { Slightly } \\
\text { warm }\end{array}$ & Neutral & Slightly cool & Cool & Cold & $\begin{array}{l}\text { No strong } \\
\text { opinion }\end{array}$ \\
\hline 3 & 2 & 1 & 0 & -1 & -2 & -3 & \\
\hline \multicolumn{8}{|c|}{ Currently, I prefer to overall feel: } \\
\hline $\begin{array}{l}\text { Much } \\
\text { warmer }\end{array}$ & Warmer & $\begin{array}{l}\text { Slightly } \\
\text { warmer }\end{array}$ & $\begin{array}{l}\text { No } \\
\text { change }\end{array}$ & Slightly cooler & Cooler & Much cooler & $\begin{array}{l}\text { No strong } \\
\text { opinion }\end{array}$ \\
\hline 3 & 2 & 1 & 0 & -1 & -2 & -3 & \\
\hline \multicolumn{8}{|c|}{ Currently, my back feels: } \\
\hline Hot & Warm & $\begin{array}{l}\text { Slightly } \\
\text { warm }\end{array}$ & Neutral & Slightly cool & Cool & Cold & $\begin{array}{l}\text { No strong } \\
\text { opinion }\end{array}$ \\
\hline
\end{tabular}




\begin{tabular}{|c|c|c|c|c|c|c|c|}
\hline 3 & 2 & 1 & 0 & -1 & -2 & -3 & \\
\hline \multicolumn{8}{|c|}{ Currently, the seat feels: } \\
\hline Hot & Warm & $\begin{array}{l}\text { Slightly } \\
\text { warm }\end{array}$ & Neutral & Slightly cool & Cool & Cold & $\begin{array}{l}\text { No strong } \\
\text { opinion }\end{array}$ \\
\hline 3 & 2 & 1 & 0 & -1 & -2 & -3 & \\
\hline \multicolumn{8}{|c|}{ Satisfaction with the thermal chair: } \\
\hline $\begin{array}{l}\text { Very } \\
\text { satisfied }\end{array}$ & Satisfied & $\begin{array}{l}\text { Slightly } \\
\text { satisfied }\end{array}$ & Neutral & $\begin{array}{l}\text { Slightly } \\
\text { dissatisfied }\end{array}$ & Dissatisfied & Very dissatisfied & $\begin{array}{l}\text { No strong } \\
\text { opinion }\end{array}$ \\
\hline 3 & 2 & 1 & 0 & -1 & -2 & -3 & \\
\hline
\end{tabular}

The occupants included twenty nine males and fifteen females mainly aged between twenty and forty years old, and four participant aged above forty. The office was mechanically ventilated open plan office in the University of Leeds. Thermal measurements were applied at the time of the survey questionnaire to evaluate the thermal environment. Thermal measuring equipment is presented in Table 2.

Table 2. Velocity and thermal measuring equipment

\begin{tabular}{|c|c|c|c|c|c|}
\hline Measurement & Time & Equipment details & Resolution & Accuracy & Range \\
\hline Velocity & Instant: at workstations & Testo425 & $0.01 \mathrm{~m} / \mathrm{s}$ & $\pm 0.03 \mathrm{~m} / \mathrm{s}$ & 0 to $20 \mathrm{~m} / \mathrm{s}$ \\
\hline Dry bulb temperature & Instant: at workstations & PCE-GA 70 meter & $0.1^{\circ} \mathrm{C}$ & $\pm 0.5^{\circ} \mathrm{C}$ & 5 to $50^{\circ} \mathrm{C}$ \\
\hline Relative humidity & Instant: at workstations & PCE-GA 70 meter & $0.1^{\circ} \mathrm{C}$ & $\pm 3 \mathrm{RH}$ & 10 to $90 \% \mathrm{RH}$ \\
\hline
\end{tabular}

\section{Results and Discussion}

Figure 9 and Figure 10 compared the predicted temperature contours of a side view cross-sectional plane inside the computational domain representing the thermal distribution around the manikin with heated office chair and normal chair. The left hand side of the plot shows the scale of airflow temperature in ${ }^{\circ} \mathrm{C}$. The contour plot in the fluid domain is colour coded and related to the CFD colour map, ranging from 22.35 to $46.85{ }^{\circ} \mathrm{C}$. As observed, the thermal chair (Figure 9) heated the seat and back rest areas between $28-36^{\circ} \mathrm{C}$. While for the case of the space heated with underfloor air jets, the temperature around the manikin range between $24-28^{\circ} \mathrm{C}$ as observed in Figure 10 . For both cases, lower temperature near the face area was observed due to higher airflow movement while a higher temperature can be observed near the seat area and thigh region due to lower air movement and constrained space. . From the results it was evident that depending on the position of the user (in this case a manikin), the seat and back rest regions had different temperature levels. Hence, there should be separate controls for the seat and backrest area to allow the user to have more control over the temperature distribution. This was implemented in the design of the chair used in the field tests. 


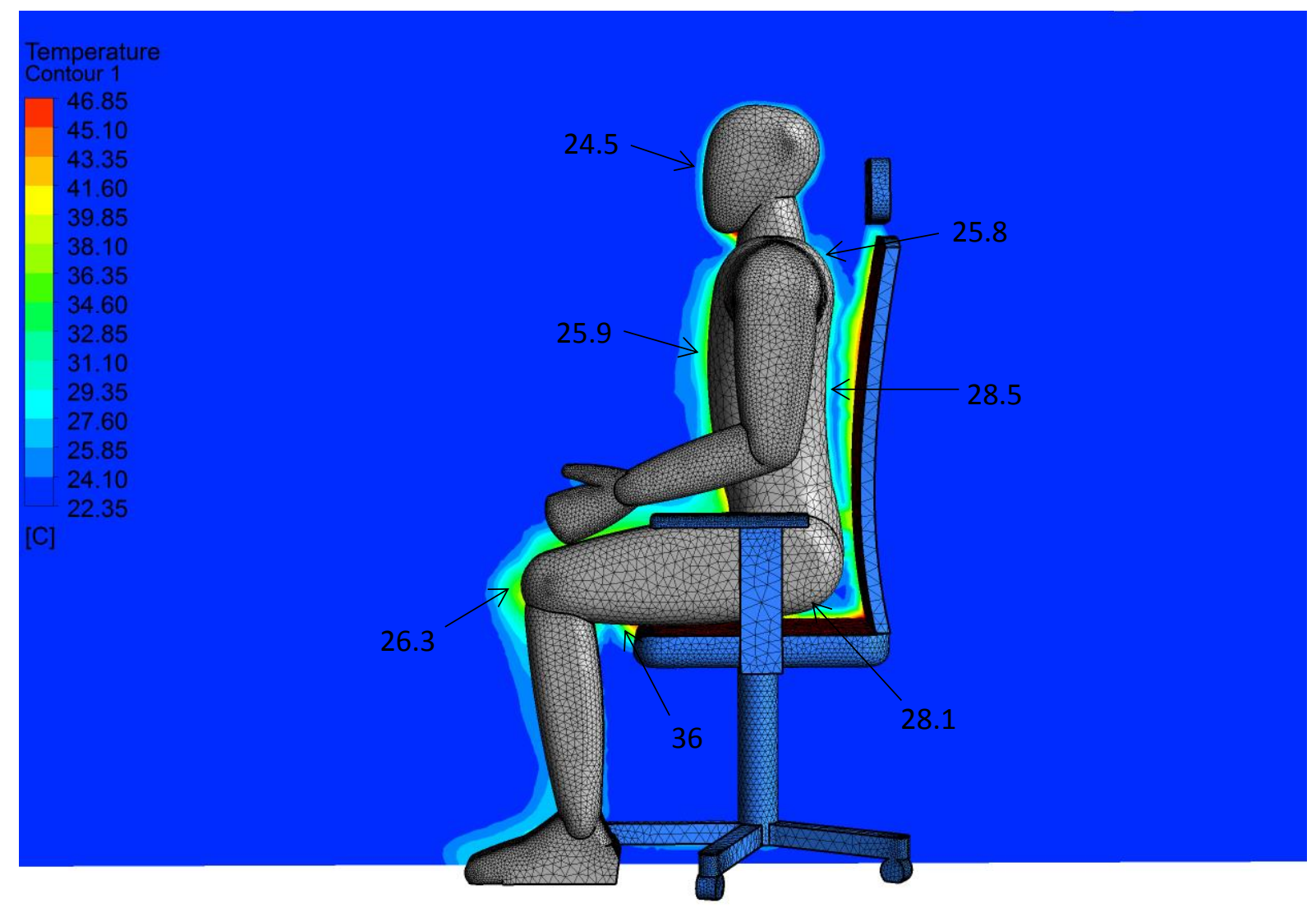

Figure 9: Cross-sectional contour showing temperature distribution around manikin with the thermal chair 


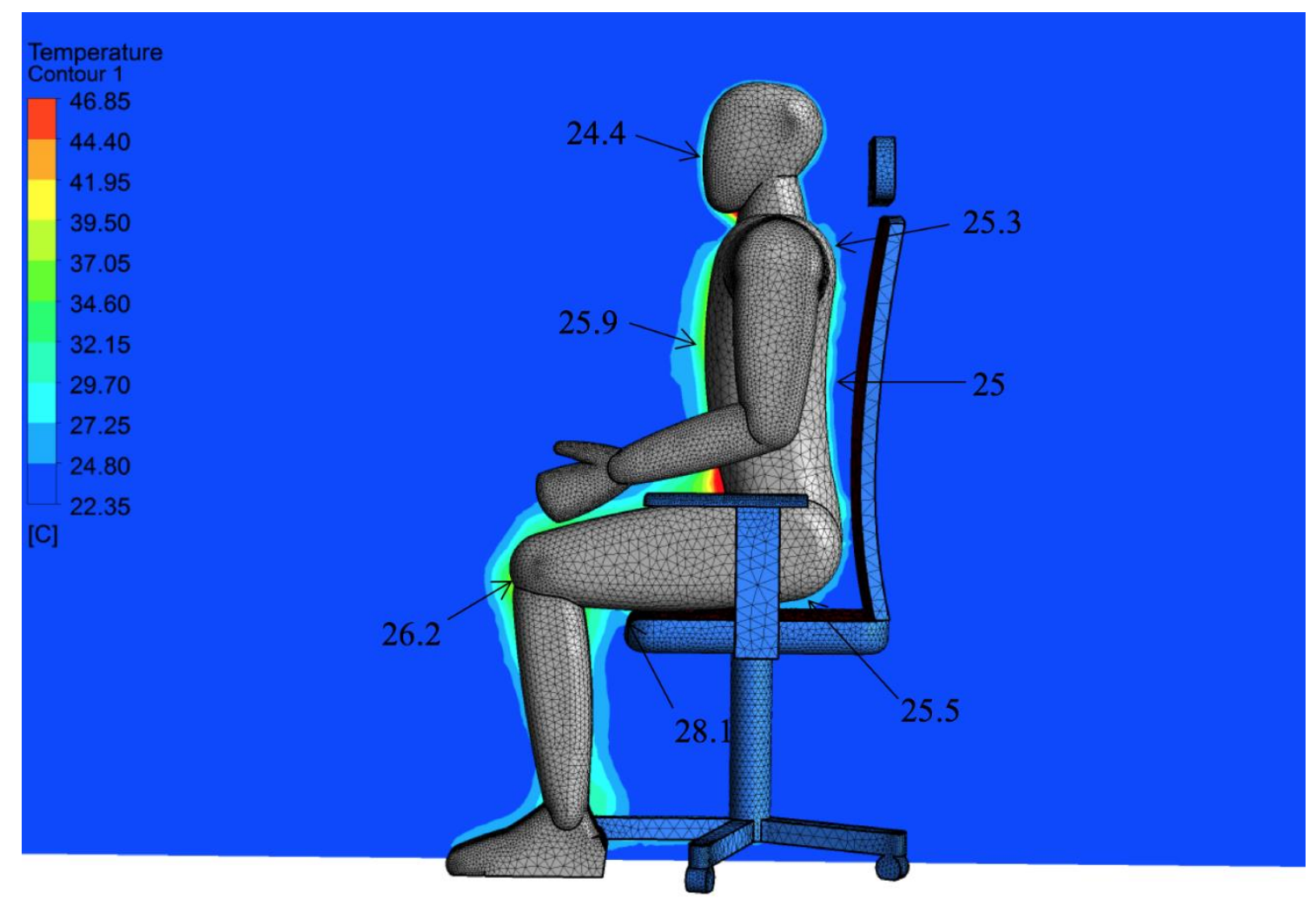

Figure 10: Cross-sectional contour showing temperature distribution around manikin with a standard non-heated office chair and underfloor air jets

Thermal comfort expresses the occupants' satisfaction with a building's thermal environment. Several models or indices have been established to predict thermal sensation and comfort and the most common of these are the Predicted Mean Vote (PMV) and Physiologically Equivalent Temperature (PET) [57]. The PMV predicts the average value of the votes of a group of occupants exposed to the similar thermal environment. It is expressed by the ASHRAE thermal sensation scale: +3 hot, +2 warm, +1 slightly warm, 0 neutral, -1 slightly cool, -2 cool and -3 cold (ASHRAE, 2013 radiant temperature, relative humidity, clothing and metabolic rate. In this study, the CFD temperature, velocity, humidity results were used to determine thermal comfort indices and assess acceptability of environmental conditions. Metabolic rate for the occupants and clothing insulation were assumed as standard values (see Table 1). Equations and derivations of the PMV are available in [58]. Table 3 summarises the predicted comfort levels in the vicinity of the manikin surfaces. Based on the PMV predictions, improved comfort levels were observed for the back area and seat area. The seat area went from -0.50 (slightly cool) to 0.08 (neutral) when the chair was heated. To further optimised the design, there should be separate controls for the seat and backrest area and this was implemented in the design of the chair used in the field tests. Thermal comfort levels 
calculated using PMV method with set values for humidity (30\%), metabolic rate (1 met), clothing (0.7).

Table 3: Predicted Mean Vote and thermal comfort levels in the vicinity of the manikin surfaces

\begin{tabular}{|l|l|l|l|l|}
\hline Body parts & With thermal chair in use & \multicolumn{2}{l|}{ Without thermal chair } \\
\hline & PMV & PPD (\%) & PMV & PPD (\%) \\
\hline Head & -0.44 (neutral) & 9 & -0.45 (neutral) & 9 \\
\hline Back/Back rest area & 0.17 (neutral) & 6 & -0.50 (slightly cool) & 10 \\
\hline Seat area & 0.08 (neutral) & 5 & -0.50 (slightly cool) & 10 \\
\hline Thigh/Upper Legs & 0.40 (neutral) & 8 & 0.40 (neutral) & 8 \\
\hline
\end{tabular}

In the field studies of thermal comfort, users' views were compared before and after using the thermal chair. Figure 11 Shows the temperature settings that the respondents arranged on the seat and the back of the chair. Only two respondents did not use the temperature of the back of the chair and three respondents had the thermostat for the seat of the chair off. Over $86 \%$ of the occupants set the temperature settings of the seat and the back of the chair between $29^{\circ} \mathrm{C}$ and $39^{\circ} \mathrm{C}$.

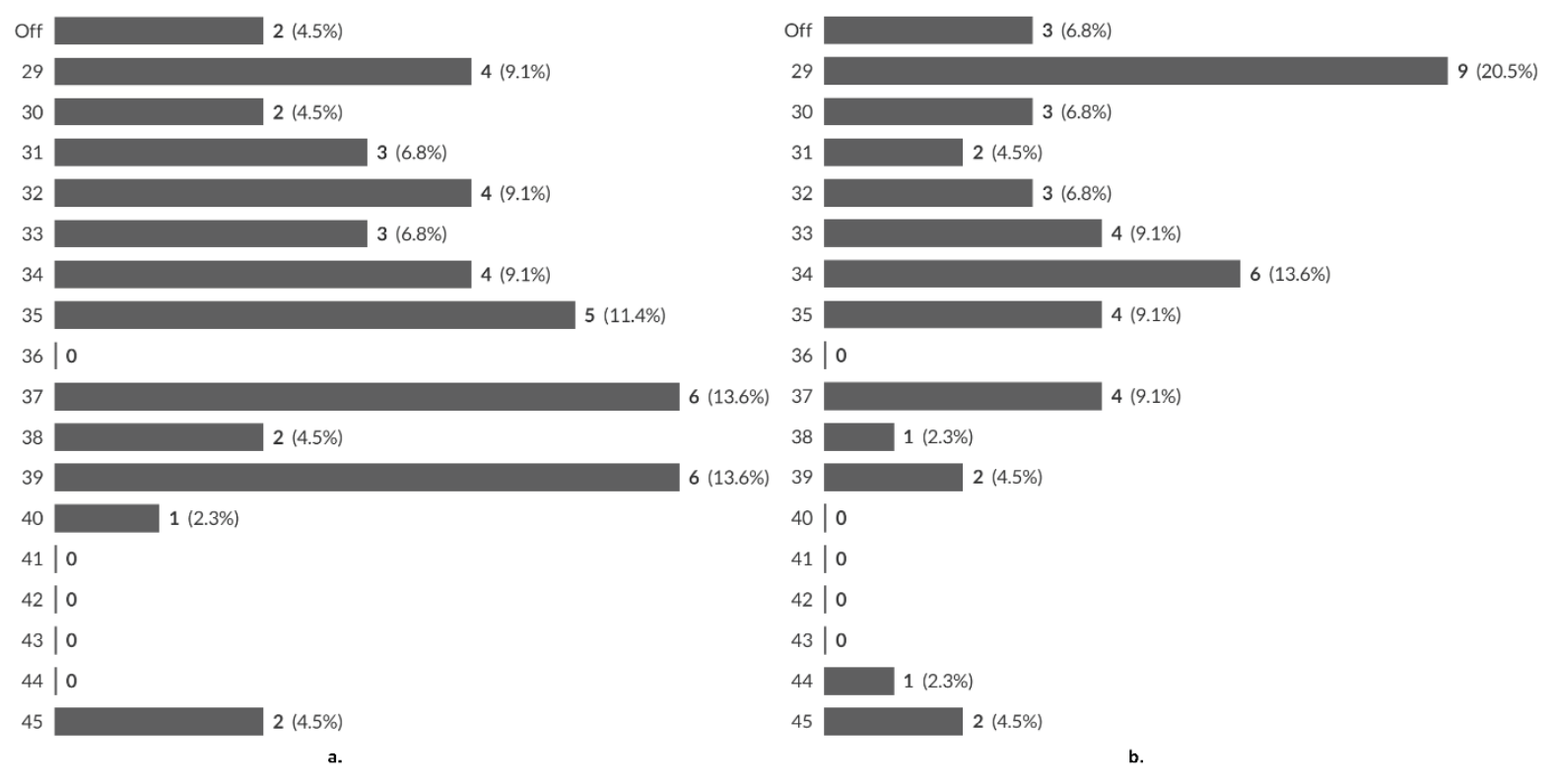

Figure 11. Temperature settings of the $a$. back and $b$. seat of the thermal chair arranged by the user

Figure 12 demonstrates thermal sensation of the user on their back and seat before and after using the chair. $68 \%$ of the occupants had a neutral and slightly warm thermal sensation before using the thermal chair and only two respondents felt warm. The rest of the occupants (23\%) felt slight cool to cold around their back. After the use of the thermal chair, still one person felt cold, but no respondents felt cool or slightly cool around their back. $98 \%$ of the occupants felt between neutral 
to hot on their back, with majority feeling slightly warm to warm. Users' respondent regarding their thermal sensation of the seat of the chair followed similar pattern. $73 \%$ of the occupants felt neutral to slightly warm before using the chair, this number shifts towards the warm side after using the thermal chair, as $86 \%$ felt neutral to hot and $45 \%$ of them felt warm around the seat of the chair. These numbers are particularly interesting as it shows that users mainly had a neutral or slightly warm local thermal sensation before the use of the thermal chair. However, after being able to adjust the temperature of the seat and the back, majority of them utilised this function and reported slightly warm to warm local thermal sensations.
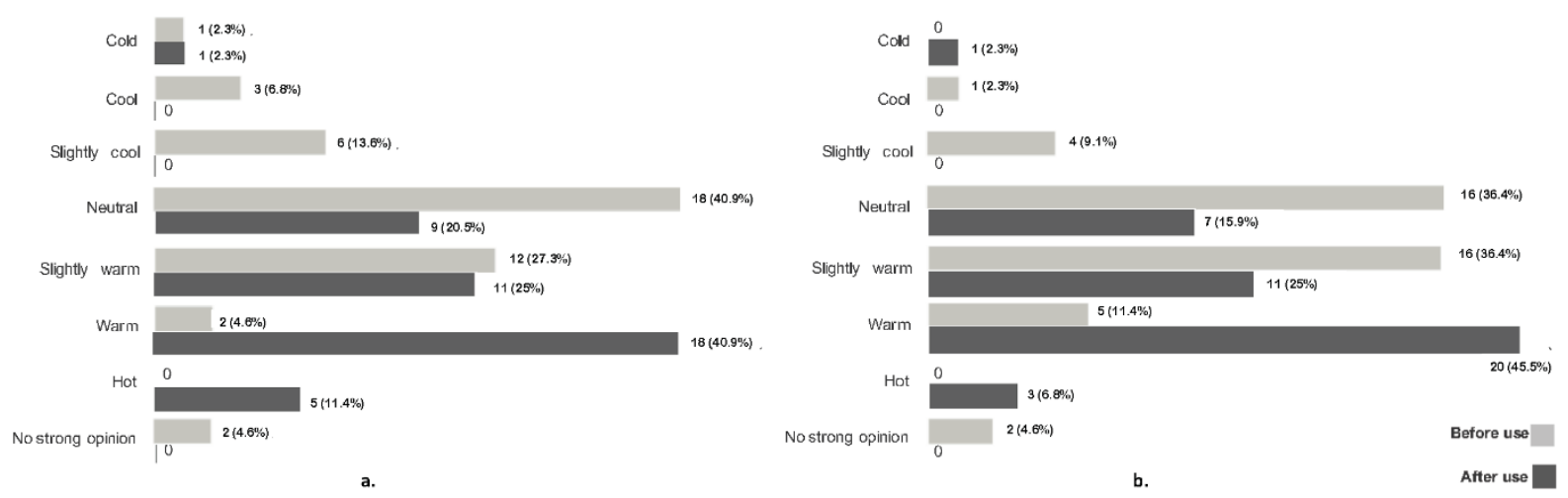

Figure 12. Thermal sensation of respondent's $a$. back and b. seat reported by the respondent before and after using the thermal chair

Respondents reported much higher comfort levels after using the thermal chair, as presented in Figure 13. The number of "comfortable" and "very comfortable" users increased from $57 \%$ to $77 \%$. The bar chart shows slightly warm or neutral thermal sensation before the experiment, while after using the chair majority of the users reported slightly warm or warm overall thermal sensations.
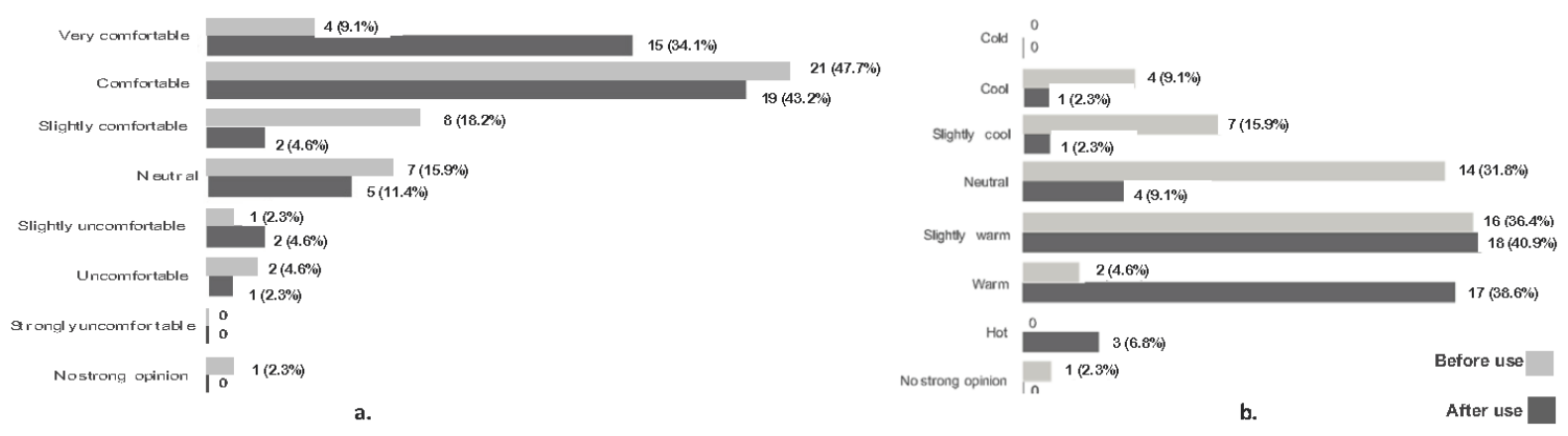

Figure 13. a. Users' views of their comfort and b. thermal sensation before and after using the thermal chair

The number of occupants feeling a neutral thermal sensation dropped from $32 \%$ to only $9 \%$, while their comfort level and satisfaction increased. Their satisfaction increased from $45 \%$ to $80 \%$, as illustrated in Figure 14. Majority of the occupants set the temperature of both the seat and the back 
between 29 to $35^{\circ} \mathrm{C} .43 \%$ reported to desire no change in the temperature and $39 \%$ preferred slightly warmer temperature. This suggested that occupants preferred to feel slightly warm to warm. $82 \%$ of the occupants expressed their satisfaction level as "satisfied" or "very satisfied" regarding the performance of the thermal chair, as demonstrated in Figure 14.

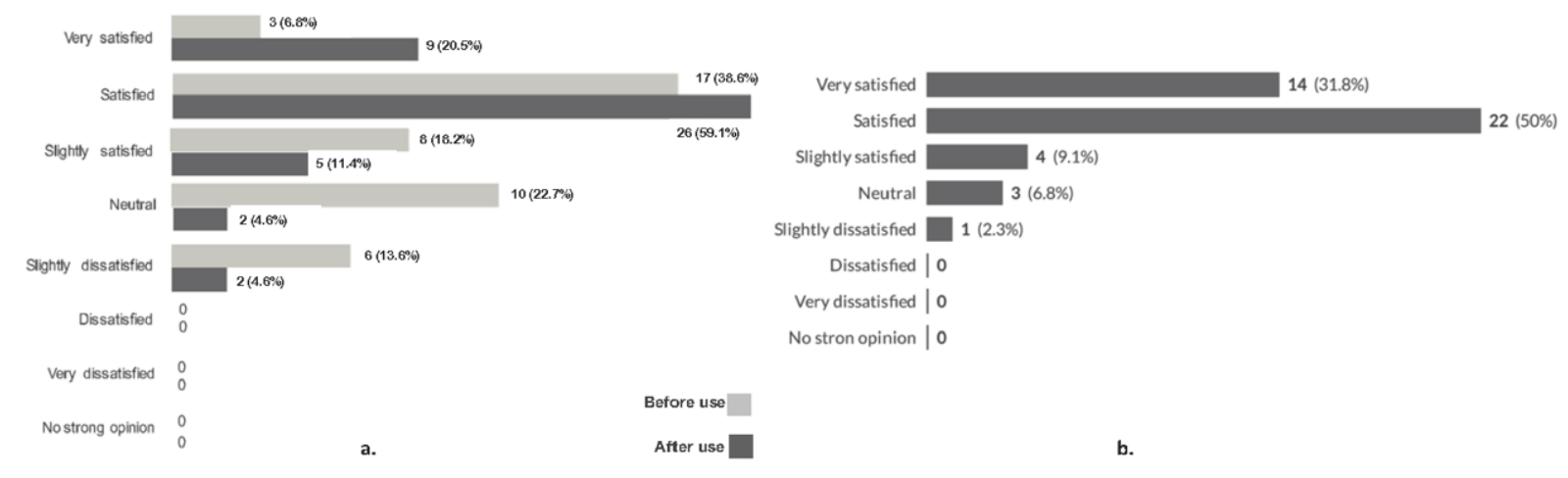

Figure 14. a. Users' overall satisfaction with the thermal environment and b. their satisfaction using the thermal chair

One of the questions focused on users' preference in having separate thermostats for the back and the seat of the chair. $86 \%$ of the respondents preferred separate controls and $14 \%$ liked an individual thermostat for the whole chair.

\section{Conclusion and Future Work}

The aim of this work was to improve user comfort and satisfaction regarding the thermal environment in the open plan office, which is a current challenge in the workplace and limited research addresses it. The work utilised Computational Fluid Dynamic (CFD) and field testing to assess thermal comfort performance of a thermal chair which allows users to control heating that is provided directly through the surfaces of seat and backrest. The CFD analysis predicted an improvement in local thermal comfort. Thermal sensation of the occupant was expected to change from slightly cool to neutral around the back, and from neutral to slightly warm around the seat. This result was to a degree in agreement with the results of the field studies, as there was a move from slightly cool and mainly neutral to slightly warm and warm after the use of the chair. Also, similar move from neutral and slightly warm towards warm was reported by the respondents after using the thermal chair. Although the results of both CFD and field studies indicated a move towards warmer thermal sensations, the CFD analysis showed a small move, while respondents reported much bigger move. The CFD analysis predicted the user's thermal comfort for the seat and backrest region as -0.50 slightly cool before and $0.08-0.17$ neutral thermal sensations after the use of the thermal chair. The field study analysis based on the occupants' responses indicated much higher 
comfort and satisfaction levels after using the thermal chair. The overall comfort level was improved by $20 \%$ and the overall satisfaction with the thermal environment was increased by $35 \%$ after using the thermal chair. $82 \%$ of the occupants expressed their satisfaction level as "satisfied" or "very satisfied" regarding the performance of the thermal chair.

The results emphasised the importance of the application of detailed CFD analysis to carry out a detailed analysis of the thermal distribution around the thermal chair providing opportunities for optimisation. From the CFD results it was evident that depending on the position of the user (in this case a manikin), the seat and back rest regions had different temperature levels. Hence, there should be separate controls for the seat and backrest area to allow the user to have more control over the temperature distribution. The CFD results showed that thermal comfort levels near the seat and back rest area were improved however it also showed that areas such as the face and legs regions cannot be improved by the current design therefore further work is necessary to redistribute the heat to other areas of the user. The results of the field studies also suggested separate thermal controls, as $86 \%$ of the respondents agreed with "do you prefer to have separate controls for back and seat?" and they mainly wanted to set the temperatures between $29^{\circ} \mathrm{C}$ and $39^{\circ}$. In addition, comparing the temperature settings on the chair and the status of thermal sensation before and after using the chair suggests that occupants preferred thermal conditions warmer than neutral for their overall thermal sensation, the thermal sensation on their back and their seat. This suggested that occupants preferred to feel slightly warm or warm and not necessarily neutral in order to feel comfortable.

The thermal chair energy consumption was relatively low $(0.03 \mathrm{~kW})$ when compared with that of typical personal heaters, which are about $1-1.5 \mathrm{~kW}$. This has a good potential for energy savings in buildings particularly during cold winter where the device could be used. This study recommends the further investigation of the thermal chair performance during different periods of the day and year. This study also recommends improvement in the CFD modelling and analysis particularly in regard to the modelling of the manikin models. Furthermore, thermal sensations other than neutral are required to be considered in thermal comfort research, CFD analysis and field studies of thermal comfort. Finally, the design of the chair requires improvement to include heating for other body parts as well as sensors for energy efficiency.

\section{Acknowledgements}

The authors gratefully acknowledge the contribution of the occupants of the case study building. 


\section{References}

[1] ANSI/ASHRAE Standard 55-2013. Thermal Environmental Conditions for Human Occupancy.

[2] Van Meel, J. 2000. The European Office. Rotterdam.

[3] Shahzad, S. 2014. Individual Thermal Control in the Workplace. University of Edinburgh.

[4] Melikov, A. 2004. Personilised Ventilation. Indoor Air, 14, 157-167.

[5] Huizenga C, Abbaszadeh S, Zagreus L, Arens E. 2006. Air Quality and Thermal Comfort in Office Buildings. Results of a Large Indoor Environmental Quality Survey. 2006;3:393-397.

[6] Hitchings, R. 2009. Studying Thermal Comfort in Context. BRI-37.

[7] Bauman, F.S., Carter, T.G., Baughman, A.V., Arens, E.A. 1998, "Field Study of the mpact of a Desktop Task/Ambient Conditioning System in Office Buildings", ASHRAE ransactions, 104, 11531171.

[8] Leaman, A. 1996. User satisfaction. Building evaluation techniques. London: McGraw.

[9] Arens, E., Humphreys, M. A., De Dear, R. \& Zhang, H. 2010. Are 'Class A' Temperatue Requirements Realistic or Desirable? Building and Environment, 45, 4-10.

[10] Shahzad, S., Brennan, J., Theodossopoulos, D., Hughes, B. and Calautit, J.K., 2017. A study of the impact of individual thermal control on user comfort in the workplace: Norwegian cellular vs. British open plan offices. Architectural Science Review, 60(1), pp.49-61.

[11] Baker, N. \& Standeven, M. 1997. A Behavioural Approach To Thermal Comfort Assessment. International Journal of Solar Energy, 19, 21-35.

[12] Shahzad, S.D., Brennan, J. and Theodossopoulos, D., 2014, January. Individual thermal control in the workplace and changes in thermal preferences in a day: Norwegian cellular vs. British open plan layouts. In Windsor Conference.

[13] Humphreys, M. A. 1972. Clothing and Thermal Comfort of Secondary School Children in Summertime. CIB Comission W45 Symposium.

[14] Nicol, F., Humphreys, M. A., Sykes, O. \& Roaf, S. 1995. Standards for thermal comfort; Indoor air temperature standards for the 21st century, London, E \& FN Spon.

[15] Humphreys, M. A. 1996. Thermal Comfort Temperatures World-Wide: The Current Position. WREC 1996.

[16] Shahzad, S., Brennan, J., Theodossopoulos, D., Hughes, B. and Calautit, J.K., 2017. Energy and comfort in contemporary open plan and traditional personal offices. Applied Energy, 185, pp.15421555.

[17] Melikov, A.K., Langkilde, G., Rasmussen, L.W. 1998. Human response to local heating for use in connection with low enthalpy ventilation. Proceedings of RoomVent. 315-321. 
[18] Tsuzuki, K., Arens, E. A., Bauman, F. S. and Wyon, D. P. 1999. Individual thermal comfort control with desk-mounted and floor-mounted task/ambient conditioning (TAC) systems, Proceedings of Indoor air '99, Vol. 2, 368-373.

[19] Akimoto, T., Lee, S., lesaki, N., Yokota, T., Hayashi, J. and Tanabe, S. 2003. Impact of nonisothermal task conditioning system on thermal comfort, Proceedings of Healthy Buildings'2003, Singapore, 776-782.

[20] Shahzad, S.S., Brennan, J., Theodossopoulos, D., Hughes, B. and Calautit, J.K., 2015. Energy Efficiency and User Comfort in the Workplace: Norwegian Cellular vs. British Open Plan Workplaces. Energy Procedia, 75, pp.807-812.

[21] Shahzad, S., Brennan, J., Theodossopoulos, D., Hughes, B., Calautit, J. K. 2016. Related Symptoms, Energy, and Thermal Control in the Workplace: Personal and Open Plan Offices. Sustainability Journal: 8: 331.

[22] Wagner, A., Gossauer, E., Moosmann, C. 2007. Thermal Comfort and Workplace Occupant Satisfaction. Energy and Building-39.

[23] Baker, N. \& Standeven, M. 1995. A Behavioural Approach to Thermal Comfort Assessment. International Journal of Solar Energy, 19, 21-35.

[24] Bordass, B., Bromley, K. , Leaman, A. 1993. User and Occupant Controls in Office Buildings. BUS.

[25] Roaf, S., Horsley, A. , Gupa, R. 2004. Closing the Loop. RIBA.

[26] Veselý, M. and Zeiler, W., 2014. Personalized conditioning and its impact on thermal comfort and energy performance-A review. Renewable and Sustainable Energy Reviews, 34, pp.401-408.

[27] Knudsen, G. L. and Melikov, A. K. (2005) "Human response to individually controlled environment", Proceedings of Indoor Air 2005, 421-425.

[28] Ahmet Uğursal, Charles H. Culp, The effect of temperature, metabolic rate and dynamic localized airflow on thermal comfort, Applied Energy, Volume 111, November 2013, Pages 64-73 [29] Liu, Y., Wang, L., Di, Y., Liu, J. and Zhou, H., 2013. The effects of clothing thermal resistance and operative temperature on human skin temperature. Journal of Thermal Biology, 38(5), pp.233-239.

[30] Ning Mao, Dongmei Pan, Zhao Li, Yingjie Xu, Mengjie Song, Shiming Deng, A numerical study on influences of building envelope heat gain on operating performances of a bed-based task/ambient air conditioning (TAC) system in energy saving and thermal comfort, Applied Energy, Volume 192, 15 April 2017, Pages 213-221

[31] Ashfaque Ahmed Chowdhury, M.G. Rasul, M.M.K. Khan, Thermal-comfort analysis and simulation for various low-energy cooling-technologies applied to an office building in a subtropical climate, Applied Energy, Volume 85, Issue 6, June 2008, Pages 449-462 
[32] Bauman, F., Webster, T., Zhang, H., Arens, E., Lehrer, D., Dickerhoff, D., Feng, J.D., Heinzerling, D., Fannon, D., Yu, T. and Hoffman, S., 2013. Advanced Integrated Systems Technology Development.

[33] Pasut, W., Arens, E., Zhang, H. and Zhai, Y., 2014. Enabling energy-efficient approaches to thermal comfort using room air motion. Building and Environment, 79, pp.13-19.

[34] Zhang, H., Arens, E. and Zhai, Y., 2015. A review of the corrective power of personal comfort systems in non-neutral ambient environments. Building and Environment, 91, pp.15-41.

[35] Pasut, W., Zhang, H., Arens, E. and Zhai, Y., 2015. Energy-efficient comfort with a heated/cooled chair: Results from human subject tests. Building and Environment, 84, pp.10-21.

[36] Pasut, W., Zhang, H., Kaam, S., Arens, E. 2013. Effect of a Heated and Cooled Office Chair on Thermal Comfort. UC Berkeley.

[37] Pigman, M. 2014. The Impact of Cooling Strategy and Personal Control on Thermal Comfort. UC Berkeley.

[38] Zhao, P., Peffer, T., Narayanamurthy, R., Fierro, G., Raftery, P., Kaam, S. and Kim, J., 2016. Getting into the zone: how the internet of things can improve energy efficiency and demand response in a commercial building.

[39] Watanabe, S., Shimomura, T. and Miyazaki, H., 2009. Thermal evaluation of a chair with fans as an individually controlled system. Building and Environment, 44(7), pp.1392-1398.

[40] Xianting, L., Junjun, L., Peng, W. and Bin, Z., 2006. Numerical Analysis on Thermal environment under Four Kinds of Chair Ventilation [J]. Heating Ventilating \& Air Conditioning, 36(5), pp.75-80.

[41] Kogawa, Y., Nobe, T. and Onga, A., 2007. Practical investigation of cool chair in warm offices. Proceedings of Clima'07.

[42] Kogawa, Y. et al. 2006. Development of Chair Mounted Iso-thermal Airflow Generator Part7:Specificaiton of "Cool Chair" 2005 Model and Outline of Subjective Experiment, Summaries of Technical Paper of Annual Meeting Architectural Institute of Japan 2006 D-2 pp.1009-1010.

[43] Onga, A. et al. 2007. Time Series Analysis of Cool Chair Operating Conditions, Proceedings of CLIMA2007, (in press)

[44] GONG, G.C., XIE, S.N., WU, J.L. and REN, Z.J., 2008. Humidity Distribution Simulation of Chair Ventilation in Large Space [J]. Journal of Hunan University (Natural Sciences), 7, p.006.

[45] Choi, H.S., Yun, S. and Whang, K.I., 2007. Development of a temperature-controlled car-seat system utilizing thermoelectric device. Applied Thermal Engineering, 27(17), pp.2841-2849.

[46] Parkhurst, G., Parnaby, R. 2008. Growth in Mobile Air-Conditioning. BRI-36.

[47] Zhang YF, Wyon DP, Fang L, Melikov AK. 2007. The influence of heated or cooled seats on the acceptable ambient temperature range. Ergonomics, 50:586-600. 
[48] Launder, B.E. and Spalding, D.B. (1974) The numerical computation of turbulent flows, Computer Methods in Applied Mechanics and Engineering, 3, 269-289.

[49] ANSYS $^{\circledR}$ Academic Research. ANSYS FLUENT User's Guide Release 15.0. Pennsylvania: ANSYS, Inc; 2015

[50] Calautit, J.K., O'Connor, D., Sofotasiou, P., Hughes, B.R. 2015. CFD Simulation and Optimisation of a Low Energy Ventilation and Cooling System. Computation, 3, 128-149.

[51] Calautit, J.K., Hughes, B.R., Shahzad, S. 2015. CFD and wind tunnel study of the performance of a uni-directional wind catcher with heat transfer devices. Renewable Energy, 83, 85-99.

[52] Yan, Y., Li, X., Yang, L., Tu, J. 2016. Evaluation of manikin simplification methods for CFD simulations in occupied indoor environments. Energy and Buildings, 127, 611-626

[53] Yan, Y., Li, X., Tu, J. 2016, Effects of manikin model simplification on CFD predictions of thermal flow field around human bodies, Indoor and Built Environment, doi:10.1177/1420326X16653500

[54] Kroner, W. M. 2006. Employee Productivity and the Intelligent Workplace. In: ClementsCroome, D. (ed.) Creating the Productive Workplace. London: Taylor \& Francis.

[55] Luo, M., Cao, B., Zhou, X., Li, M., Zhang, J., Ouyang, Q. and Zhu, Y., 2014. Can personal control influence human thermal comfort? A field study in residential buildings in China in winter. Energy and Buildings, 72, pp.411-418.

[56] ASHRAE 2009. ASHRAE Handbook: Fundamentals. SI Edition ed. Atlanta: American Society of Heating, Refrigerating and Air-Conditioning Engineers, Inc.

[57] ISO, ISO 7730: 2005. Ergonomics of the thermal environment - analytical determination and interpretation of thermal comfort using calculation of the PMV and PPD indices and local thermal comfort criteria

[58] ASHRAE, ASHRAE Standard 55-2010: Thermal Environmental Conditions for Human Occupancy. Atlanta: American Society of Heating, Refrigerating and Air-Conditioning Engineers, 2010. 